Museum at Leningrad, opened in 1931 and containing collections illustrative of the progress of the geological survey of the U.S.S.R.; and the Karpinsky Geological Museum at Moscow, opened in 1934 and containing 72,250 specimens of minerals. These are arranged in five separate collections: systematic, geochemical, genetic, crystallographic and applied. Another interesting aspect of the status of geology in the U.S.S.R. is the establishment in 1920 of the Ilmen National Park in the southern Urals for the preservation and study of the famous mineral localities of precious stones and other minerals as well as flora and fauna.

The progress made in the U.S.S.R. in the utiliza. tion of mineral wealth is described independently in a short article by V. I. Kryzhanovsky ${ }^{2}$, in which he gives a review of the achievement in the exploration and utilization of various ores. Only a few outstanding examples can be given here: the discovery of very rich iron ore at Magnitogorsk in the southern Urals, nickel and titanium in the southern Urals and Kola peninsula, molybdenum and tungsten ores in Siberia and Central Asia, bauxite at Tichvin (near Leningrad) and the Urals, tin ore (previously unknown in the U.S.S.R.) in Central Asia. There is also a description of the progress made in the prospecting and mining of gold, platinum, uranium, radium, manganese, coal and oil, borates, etc. But probably the most spectacular discoveries are those of apatite in the Kola peninsula and potash salts in the Urals, both of them of great importance in agriculture. The apatite deposits of the Kola peninsula, discovered in 1921, are the richest in the world, with an estimated reserve of 2,000 million tons. Since this discovery, a now industrial area with two new thriving towns has sprung up in a previously deserted arctic tundra. Besides apatite, a, number of other minerals were discovered in the Kola peninsula, such as nepheline, pyrrhotite, titanium ores, ores of rare elements, kyanite, garnet, etc.

The discovery of potash salts at Solikamsk in the northern Urals is no less spectacular. The reserves of sylvite at Solikamsk are estimated to be five times greater than those at Stassfurt in Germany, hitherto regarded as the richest deposit in the world, and still more deposits are being discovered as the survey progresses.

The mineral wealth of the U.S.S.R., always known to be enormous, is rapidly coming within reach of the miner and thus provides a solid foundation for an ever increasing industrialization. The contributions made by geologists and miners to the defence of their country are thus inestimable. S. I. TomkeIFFr.

" "The Progress of Geological and Geographical Sciences in the U.S.S.R during Twenty-five Years". In Russian. Edited by V. A. Obruchev (Moscow-Leningrad: Academy of Sciences of the U.S.S.R., 1943.)

${ }^{2}$ Kryzanovsky, V. I. "Les fossiles et la defence de l'URSS", Bull. Acad. Sci. URSS., Ser. Geol., No. 6, 3 (1941).

\section{CHEMISTRY IN RELATION TO MEDICINE}

$\mathrm{I}^{\mathrm{N}}$ I a recent lecture before the Royal Institute of Chemistry* on some recent advances in chemistry in relation to medicine, $D$. H. Hey gives an interesting and coneise account of the astonishing contributions which have been made in this field during the

* "Some Recent Advances in Chemistry in Relation to Medicine". By Dr. D. H. Hey. Pp. 24. (London: Royal Institute of Chemistry, 1944. last ten years. The beginning of this century saw the introduction of the first therapeutic compound of major importance which had been made to the chemist's design, namely, aspirin, first made in 1899 . At the present rate of progress, Dr. Hey suggests, the present major diseases and scourges of mankind will be completely controlled well before the end of this century. This will seem to some medical men an optimistic prophecy; but certainly recent work gives every reason to hope for its realization. One difficulty, however, is that the human talent which slays these dragons so rapidly discovers almost as quickly new causes of disease which defeat existing remedies; and although we may banish the major scourges, we should give equal attention to the minor ones, some of which cause incalculable unhappiness and economic loss and are untouched by our most efficient therapeutic compounds - the 'common cold', for example.

Dr. Hey deals with the sulphonamides, the amidines, the antibiotics (such as penicillin) and the steroid hormones (testosterone, cestradiol and progesterone). "It is no exaggeration to say that the new sulphonamide derivatives prepared during the last seven or eight years can be numbered by the thousand, but the vast majority of these have never been tested in vivo". The author explains how the chemist has juggled with the sulphonamide hydrogen atoms in the sulphonamide molecule to produce sulphapyridine, sulphathiazole and other compounds which are now being widely used, and he discusses the properties and bacteriostatic actions of these.

The history of the development of the amidines illustrates the tortuous paths by which final success is sometimes attained. Hey traces the origin of the work on the amidines to an early observation by Koch on parathyroid tetany. Methylguanidine was found in the urine of animals suffering from this, and it was found that administration of methylguanidine or of guanidine caused a fall in blood sugar. Guanidine compounds of greater activity but less toxicity were then sought out, and synthalin and synthalin B were introduced for the oral treatment of diabetes; but they caused too much damage to the liver. It was also found that trypanosomes consume, in artificial cultures, large quantities of glucose, and it was hoped that synthalin, by reducing the blood sugar, would interfere with the development of the trypanosomes and so would be useful for the treatment of sleeping sickness. Lourie and Warrington Yorke found that it did affect the trypanosomes, but not because it reduced the blood sugar but because it was trypanocidal, while insulin was not. This led to the discovery of less toxic drugs of this type, some of which have been tried for the treatment of trypanosomiasis and also, by virtue of their antibacterial action, for the treatment of burns and wounds. The Lancet (796, June 17, 1944), for example, discusses the use of propamidine $\left(4: 4^{\prime}\right.$-diamidinodiphenoxypropane) for the treatment of sepsis in burns and wounds, pointing out that the work of F. R. Selbie and J. MeIntosh (J. Path. and Bact., $55,477 ; 1943)$ and of J. W. Allen, F. Burgess and G. R. Cameron (ibid., 56, 217; 1944) and of others indicates that the toxicity of this drug requires care in its use and selection of suitable cases. The British Medical Journal (725, May 27, 1944) discusses the relative advantages and disadvantages of the diamidines and antimonial compounds for the treat. ment of kala-azar and gives further references to the literature about them. 
The blood anti-coagulants heparin and dicoumarin provide an equally interesting story. People receiving large and continued doses of salicylates should also receive vitamin $K_{1}$ or some related compound which will, by maintaining the synthesis of prothrombin in the blood, counteract the anti-coagulant action of salicylic acid due to its reduction of prothrombin. The fact that dicoumarin can be degraded to salicylic acid completes the story.

The author's treatment of the genital hormones is no less interesting and illuminating. The diagrams of the rnolecular structure of the compounds described help the inexpert reader very considerably.

\section{G. LAPage.}

\section{RADIO PLANNING IN THE U.S.A.}

$\mathrm{T}$ HE present War has been accompanied by great advances in the application of radio technique to communications and other purposes, and much thought is already being given to the conversion of the results of this work to peace-time conditions. Among the major problems of a post-war world will be the allocation of different portions of the radiofrequency spectrum among the various interests involved, and the consideration of the trend of broadcasting with both amplitude and frequency modulation, and of television. In the United States of America, the body responsible for frequency allocation and for controlling the standards used in the systems developed for the various radio services is the Federal Communications Commission; and in November 1942 the chairman of the Commission, Mr. J. L. Fly, suggested that an organization representative of the radio industry and of the personnel involved therein might be set up to consider the technical requirements of the future in the field of radio. Accordingly, a Radio Technical Planning Board (R.T.P.B.) was set up during 1943 ; and an account of the organization and work of this body to date has been given by its chairman, Dr. W. R. G. Baker, in the June issue of the General Electric Review (U.S.A.).

The objectives of the Board are stated to be the formulation of sound engineering principles and the organization of technical facts which will assist in the development, for the public interest, of the radio industry and the radio services of the nation. The sponsors of the Radio Technical Planning Board are those non-profit-making associations and societies which have an important interest in radio and which indicate a willingness to co-operate in achieving the objectives of the Board. At the present time, there are twelve such bodies which contribute an annual sum of 1,000 dollars or more towards the expenses of the Board, while in addition, there are six noncontributing sponsors.

The article referred to above contains an illustrated detailed account of the organizational structure of the Board and its constituent panels, involving a total personnel of about six hundred at the present time. Under the staff and administrative committee, thirteen panels have been set up to deal with subjects covering the whole field of radio communication, broadcasting, television, facsimile, navigation and the use of high-frequency equipment for industrial, medical and scientific purposes. Each panel is under the chairmanship of a leading engineer in the particular branch of radio concerned, and he is assisted by the most competent specialists available.

An illustrated coloured chart accompanying the article shows that the frequency spectrum with which the Radio Technical Planning Board is concerned extends from 40 kilocycles per second to at least 500 megacycles per second. In view of this broad field, and the number of individuals involved, it is perhaps unlikely that there will be a preponder. ance of unanimous recommendations emanating from the work of the Board. Even in the absence of very many strong majority proposals, it is considered that the work of the Board will serve a useful purpose in bringing to light many controversial points and in amassing and disseminating a large amount of technical data and information which will be of undoubted value in the planning of radio applications after the War.

\section{THE NILE BASIN}

$I^{\mathrm{N}}$ recent years the Egyptian Government has published various monographs dealing with the Nile and its waters, including Dr. J. Ball's "Contributions to the Geography of Egypt". Now Dr. H. E. Hurst, director-general of the Physical Department, has compiled a general non-technical account of what is known of the Nile basin and the floods of the Nile, as well as an account of the various barrages*. The publication is well illustrated by one coloured and several black and white maps and diagrams. There is, however, no bibliography.

The Nile basin, embracing about one tenth of the area of Africa, extends far beyond the confines of Egypt; but its most-important aspects are peculiar to Egypt and the Anglo-Egyptian Sudan. A brief historical survey might perhaps have stressed how near the truth Ptolemy came regarding the sources of the Nile, though he was largely discredited until the end of the nineteenth century. The physical history of the river is sketched and Ball's hypothesis of Lake Sudd is discredited. The discovery of flint implements a few metres above the present level of the river at Khartoum is a blow to the theory of a lake which existed until a late date, when it was supposed to have overflowed to the north and joined the Bahr-el-Jebel and Blue Nile waters to the Nile. The distribution of early implements suggests that the stone people of the Nile valley probably lived in a warm and humid climate. Since that climate changed to its present character, Dr. Hurst believes that there is no evidence of periodic changes, though there are irregularities from year to year. Nor does he find any connexion, which has been suggested, between sunspot activity and Nile flow or the level of Lake Victoria.

While the hydrology of the Nile is fairly well known, there is still a little uncertainty about the origin of the rainfall which causes the floods. Abyssinia provides 84 per cent of all Nile water and 70 per cent of flood water; but the old theory that this water originates from the Indian Ocean monsoon seems to be fallacious. Rainfall on the east and south of the Abyssinian plateau is scanty compared with that on the west, to which, in the flood season, the winds blow across Africa from the Gulf of Guinea. It seems

* Ministry of Public Works, Egypt: Physical Department Paper No. 45. A Short Account of the Nile Basin. By Dr. H. E. Hurst. Pp. iv $+77+9$ plates. (Cairo: Government Press, 1944.) P.T.40. 